\title{
Uremic encephalopathy with isolated brainstem involvement revealed by magnetic resonance image: a case report
}

\author{
Li-jing Jia ${ }^{1,2,3^{*}}$ (D), Zhen-zhen Qu ${ }^{1,2,3}$, Xue-qian Zhang ${ }^{1}$, Yu-juan Tian ${ }^{1}$ and Ying Wang ${ }^{1}$
}

\begin{abstract}
Background: Uremic Encephalopathy (UE) is a neurological complication associated with acute or chronic renal failure. Imaging findings of UE may present involvement of the basal ganglia, cortical or subcortical regions, and white matter. We report a rare case of UE caused by neurogenic bladder with isolated brainstem involvement revealed by magnetic resonance imaging (MRI). Immediate therapy resulted in full recovery of neurological signs and changes on MRI.
\end{abstract}

Case presentation: A 14-year-old Han Chinese woman with a history of chronic renal failure caused by neurogenic bladder. On admission, she was unconscious and her pupils presented different sizes, while her vital signs were normal. MRI showed high signal in the dorsal pontine base and in the mid brain on fluid-attenuated inversion-recovery (FLAIR) imaging and on T2-weighted imaging while the signal was normal on diffusion-weighted images (DWI). Blood analysis revealed renal failure and acidosis. After urinary retention treatment and acidosis correction, the patient soon recovered. Follow-up MRI 2 months after the discharge revealed complete resolution of UE in the brainstem.

Conclusion: We reported a rare case of a patient with UE that had unusual imaging manifestations for whom timely diagnosis and treatment assured recovery.

Keywords: Uremic encephalopathy, Magnetic resonance images, Brainstem, Renal failure, Posterior reversible encephalopathy syndrome

\section{Background}

Uremic encephalopathy (UE) may result from multiple disorders associated with acute or chronic renal failure and is characterized by acute or subacute onset of reversible neurological symptoms. There are 3 patterns of imaging findings in patients with UE: involving the basal ganglia, cortical or subcortical regions, and white matter [1]. Cortical involvement of UE is a category of posterior reversible encephalopathy syndrome (PRES) and basal ganglia involvement is rare $[1,2]$, the white matter involvement is limited to case reports [3, 4]. We came across a reported case of UE caused by neurogenic bladder that presented isolate involvement of the brainstem on magnetic resonance imaging (MRI). To our knowledge,

\footnotetext{
* Correspondence: jlj997@126.com

'Department of Neurology, The Second Hospital of Hebei Medical University, Hebei, Shijiazhuang 050000, People's Republic of China

${ }^{2}$ Institution of Cardiocerebrovascular Disease, Hebei, West Heping Road 215,

Shijiazhuang 050000, People's Republic of China

Full list of author information is available at the end of the article
}

only two other reported cases had MRI findings similar to this patient $[5,6]$. We report a rare case of UE with unusual imaging manifestation to encourage timely diagnosis and treatment of this condition.

\section{Case presentation}

A 14-year-old Han Chinese woman with a history of neurogenic bladder for more than 10 years was admitted to our Department because of coma for $12 \mathrm{~h}$. The patient complained for diplopia without fever or diarrhea 4 days before her coma with no incentive. She had no limb weakness and was treated with Vitamin Bland mecobalamine. Her previous medical history included neurogenic bladder caused by spina bifida occulta for 12 years and hydronephrosis diagnosed 1 year before. Sometimes she had urine retention, but she received no treatment for the neurogenic bladder except for urethral catheterization occasionally. She had no seizures and no fever. On admission, physical examination revealed that she was unconscious. The pupils did not react to light 
and presented different sizes in each eye (left pupil diameter, $2.5 \mathrm{~mm}$; right pupil diameter, $4 \mathrm{~mm}$ ). On stimulation, she could move her 4 limbs spontaneously. There were exaggerated deep tendon reflexes over both legs and the right Barbinski sign was positive. However, her vital signs were stable: Blood Pressure (BP) was 120/ $81 \mathrm{mmHg}$; pulse rate, 76 beats/min; body temperature, $36.5^{\circ} \mathrm{C}$; breath, 12 times/min. Non-contrast brain computed tomography (CT) after the onset of her coma revealed diffuse brain stem hypodensity. Brain MRI acquired $4 \mathrm{~h}$ after the coma onset in the county hospital showed high signal at the dorsal part of the pontine base and the mid brain on fluid-attenuated inversionrecovery (FLAIR) imaging and T2-weighted imaging. However, diffusion-weighted images presented normal signal (Fig. 1). The non- contrast abdominal CT preformed on the next day of admission showed chronic obstructive uropathy with a distended bladder, severe hydronephrosis and dual renal atrophy.

Blood analysis immediately after admission revealed renal failure [Urea nitrogen: $23.87 \mathrm{mmol} / \mathrm{L}$, Creatinine: $566.8 \mu \mathrm{mol} / \mathrm{L}$ ], and anemia [RBC: $2.5 \times 10^{12} / \mathrm{L}, \mathrm{HGB}$ : $79 \mathrm{~g} / \mathrm{L}]$. Arterial blood gas analysis revealed metabolic acidosis [pH 7.09 (7.35-7.45)]. Liver function was normal.

The patient was diagnosed with UE due to chronic renal failure and metabolic acidosis. She was immediately treated with $200 \mathrm{ml}$ of bicarbonate at $5 \%$ conducted by quick intravenous injection, followed by $100 \mathrm{ml}$ intravenous injection of bicarbonate at $5 \%$ once a day and $1.0 \mathrm{~g}$ of bicarbonate administered orally three times per day for 3 days. Simultaneously, she underwent urethral catheterization to relieve the urine retention. She was revived without diplopia 3 days after admission and the reviewed blood analysis after urethral catheterization showed that her renal function was returning to a normal level (Urea nitrogen: $13.10 \mathrm{mmol} / \mathrm{L}$, Creatinine: $294 \mu \mathrm{mol} / \mathrm{L}$ ); hence, dialysis was not necessary. She was treated with hypodermically administered erythropoietin $3000 \mathrm{u}$ twice a day, and ferrous sulfate $0.3 \mathrm{~g}$ orally thrice a day for the anemia. She was discharged
14 days after the admission without diplopia and any mental disturbance. She was still with the ureteral catheter because of the hydronephrosis. Two weeks after the discharge, the catheter was removed when abdomen ultrasonic showed decreased hydronephrosis. Follow-up MRI performed 2 months after the discharge revealed complete resolution of the brainstem UE (Fig. 2). Reviewed blood analysis after 2 months of discharge showed that her renal failure still persisted (Urea nitrogen: $13.10 \mathrm{mmol} / \mathrm{L}$, Creatinine: $190.3 \mu \mathrm{mol} / \mathrm{L}$ ). However, she had no neurological disturbance or urinary retention. She underwent the comprehensive bladder-retraining program to avoid urinary retention and her renal function was regularly assessed once a month.

\section{Discussion and conclusions}

Clinical manifestations of UE are variable and alterations in brain images play an important role in the diagnosis of the condition. Unusual for typical UE imaging manifestations, the imaging findings of our patient showed isolated brainstem hyperintensity on FLAIR and T2WI without basal ganglia and cortical or subcortical involvement. As opposed to the typical posterior reversible encephalopathy syndrome (PRES), central-variant posterior reversible encephalopathy syndrome had been described as brain stem or basal ganglia involvement that spares the cerebral cortex and subcortical white matter [7], which had similar imaging features with our patient. Approximately one-third of PRES cases are reported to have involved the brainstem and basal ganglia, accompanied by involvement of the parieto-occipital regions [8] and only $4 \%$ of these patients did not have cortical involvement [7]. As for UE, there were few reports on the isolated brain stem involvement detectable through MRI. Although the brainstem was involved and the patient presented severe symptoms, timely and accurate therapy resulted in clinical recovery.

Although the pathophysiological changes are not fully understood, UE and PRES share similar clinical and MRI features. The pathophysiology of PRES is thought to be

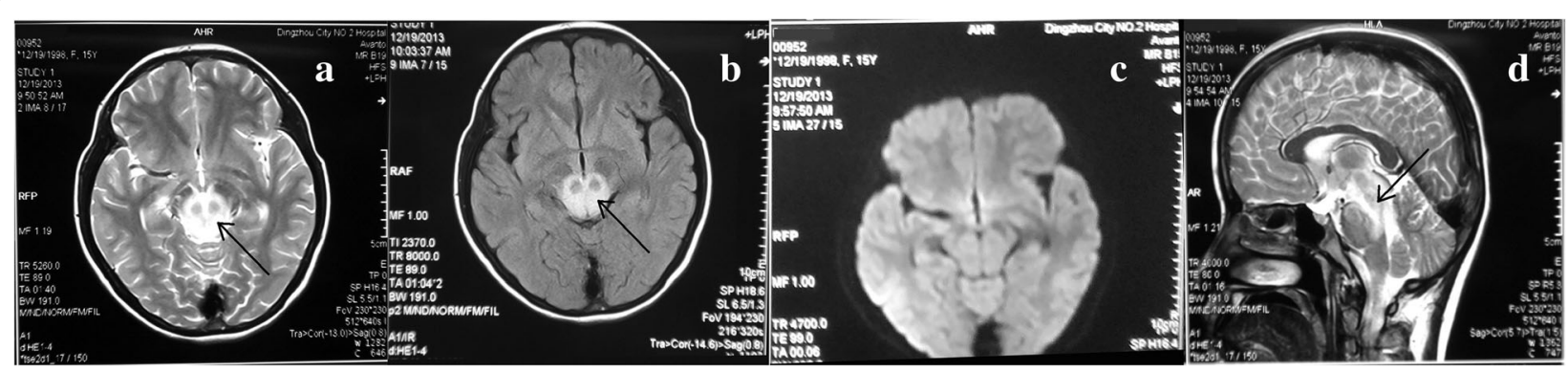

Fig. 1 Brain MRI after the symptom onset. T2-weighted imaging (T2WI) and fluid-attenuated inversion-recovery (FLAIR) imaging revealed isolated hyperintense signals in the dorsal part of the pons and the midbrain in axial view (a, b) and sagittal view (d). Diffusion-weighted imaging (DWI), however, showed normal intensity (c) 


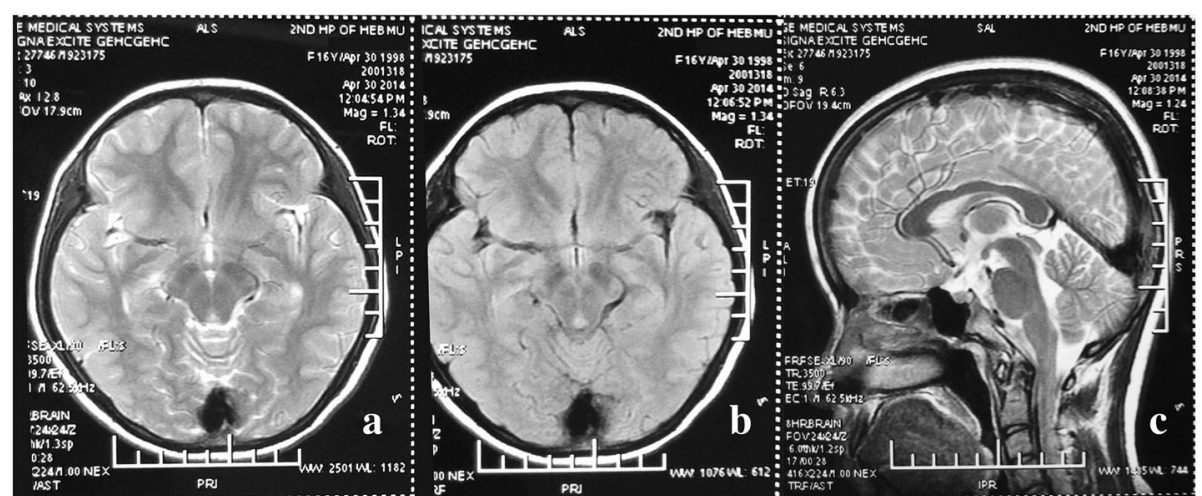

Fig. 2 Follow up magnetic resonance imaging (MRI) showed significant decrease in signal intensity in the brainstem on axial T2-weighted imaging (T2WI) (a), axial fluid-attenuated inversion-recovery (FLAIR) imaging (b), and sagittal T2WI (c)

the dysfunction of vascular autoregulation whereas UE is likely caused by the effects of neurotoxic compounds [1]. Regardless the reason, the breakdown of the bloodbrain barrier is the key factor of the imaging manifestations [9]. MRI predominantly reveals vasogenic edema but cytotoxic edema has been reported in UE and PRES $[1,3,4]$. The imaging manifestations of our patient showed hyperintensity on T2WI and FLAIR but normal intensity on DWI, which represented vasogenic edema. We assumed that this image finding may be caused by the breakdown of the blood-brain barrier related to the uremic toxin or acidosis. When the acidosis was corrected ( $\mathrm{PH}$ 7.42) and the renal failure decreased (Urea nitrogen: $14.6 \mathrm{mmol} / \mathrm{L}(1.7-7.1 \mathrm{mmol} / \mathrm{L})$, Creatinine: $294 \mu \mathrm{mol} / \mathrm{L}(0.1-136 \mu \mathrm{mol} / \mathrm{L})$, after the urinary obstruction was relieved 3 days after the admission, the clinical symptoms of the patient resolved. Follow-up images acquired 2 months after the discharge showed complete resolution of the brainstem even though the renal failure was not completely recovered (Urea nitrogen: $13.10 \mathrm{mmol} / \mathrm{L}$, Creatinine: $190.3 \mu \mathrm{mol} / \mathrm{L}$ ). However, we are not able to comment on why the lesion was located in the brain stem without cortical or basal ganglia involved.

The brainstem CT and MRI findings in our patient should be differentiated from Wernicke's encephalopathy, central pontine myelinolysis, and infectious brainstem encephalitis. The lack of no increased signal in periaqueductal regions and medial thalami make Wernicke's encephalopathy unlikely. Infectious encephalitis was ruled out, because there was no fever and other signs of infection. The reversibility of symptoms and imaging findings coupled with a negative history of rapid correction of hyponatremia makes central pontine myelinolysis less likely.

UE in renal failure is reversibly associated with hemodialysis or peritoneal dialysis, which removes neurotoxic compounds. Regarding our patient, her renal failure was caused by neurogenic bladder related to spina bifida occulta. It is reported that among nearly 60,000 patients with neurogenic bladder, the incidence of lower urinary tract infections was $29-36 \%$, urinary retention was $9-14 \%$, and urinary tract obstructions was $6-11 \%$ [10]. Our patient had urinary retention and urinary tract obstruction and she presented UE when the renal function got very severe. After the urinary retention was relieved by urethral catheterization and the acidosis was corrected, the renal function improved and the clinical manifestations were recovered without dialysis.

In summary, MRI manifestations are important for the diagnosis of UE. Neurotoxic compounds and metabolic acidosis may play roles in the pathophysiology of this disease. We reported a rare case of a patient with UE that had isolated brainstem vasogenic edema detectable through MRI, assuring timely diagnosis and treatment of the condition.

\section{Abbreviations}

MRI: Magnetic resonance imaging; PRES: posterior reversible encephalopathy syndrome; UE: uremic encephalopathy, renal failure

\section{Acknowledgements}

We thank the patient and her father for their collaboration.

\section{Funding}

The design of the study and collection, analysis, and interpretation of data and in writing the manuscript was supported by research grants from the second hospital of Hebei medical university foundation (2h1201612).

Availability of data and materials

All data related to this case report are contained within the manuscript.

\section{Authors' contributions \\ Study concept and design: LJ, Acquisition of data: ZZQ, XQZ, YJT. YW. All authors read and approved the final manuscript.}

Ethics approval and consent to participate

This case report was approved by the Ethical Committee of the second Hospital of Hebei Medical University.

\section{Consent for publication}

Written informed consent was obtained from the patient's farther for publication of this Case Report and any accompanying images. A copy of the written consent is available for review by the Editor of this journal. 


\section{Competing interests}

The authors declare that they have no competing interests.

\section{Publisher's Note}

Springer Nature remains neutral with regard to jurisdictional claims in published maps and institutional affiliations.

\section{Author details}

'Department of Neurology, The Second Hospital of Hebei Medical University, Hebei, Shijiazhuang 050000, People's Republic of China. ${ }^{2}$ Institution of Cardiocerebrovascular Disease, Hebei, West Heping Road 215, Shijiazhuang 050000, People's Republic of China. ${ }^{3}$ Neurological Laboratory of Hebei Province, Hebei, Shijiazhuang 050000, People's Republic of China.

Received: 9 May 2017 Accepted: 1 August 2017

Published online: 08 August 2017

\section{References}

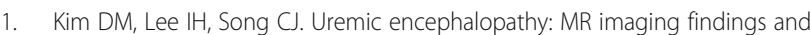
clinical correlation. Am J Neuroradiol. 2016:37:1604-9.

2. Graham BR, Pylypchuk GB. Posterior reversible encephalopathy syndrome in an adult patient undergoing peritoneal dialysis: a case report and literature review. BMC Nephrol. 2014;15:10.

3. Kang E, Jeon SJ, Choi SS. Uremic encephalopathy with atypical magnetic resonance features on diffusion-weighted images. Korean J Radiol. 2012; 13(6):808-11.

4. Pruss H, Siebert E, Masuhr F. Reversible cytotoxic brain edema and facial weakness in uremic encephalopathy. J Neurol. 2009;256:1372-3.

5. Osman Y, Imam Y Z, Salem K, Al-Hail H, Uthman B, Deleu D. Isolated brainstem involvement in a patient with hypertensive encephalopathy. Case Rep Neurol Med. 2013; Article ID 540947.

6. Shiga Y, Kanaya Y, Kono R, Takeshima S, Shimoe Y, Kuriyama M. Posterior reversible encephalopathy syndrome of the midbrain and hypothalamus - a case report of uremic encephalopathy presenting with hypersomnia. Rinsho Shinkeigaku. 2016;56:43-7.

7. Makinney AM, Jagadeesan BD, Truwit CL. Central-variant posterior reversible encephalopathy syndrome: brainstem or basal ganglia involvement lacking cortical or subcortical cerebral edema. AJR. 2013;201:631-8.

8. Liman TG, Bohner G, Heuschmann PU. The clinical and radiological spectrum of posterior reversible encephalopathy syndrome: the retrospective Berlin PRES study. J Neurol. 2012;259:155-64.

9. Fugate JE, Rabinstein AA. Posterior reversible encephalopathy syndrome: clinical and radiological manifestations, pathophysiology, and outstanding questions. Lancet Neurol. 2015;14:914-5.

10. Manack A, Motsko SP, Haag-Molkenteller C. Epidemiology and healthcare utilization of neurogenic bladder patients in a US claims database. Neurourol Urodyn. 2011;30:395-401.

\section{Submit your next manuscript to BioMed Central and we will help you at every step:}

- We accept pre-submission inquiries

- Our selector tool helps you to find the most relevant journal

- We provide round the clock customer support

- Convenient online submission

- Thorough peer review

- Inclusion in PubMed and all major indexing services

- Maximum visibility for your research

Submit your manuscript at www.biomedcentral.com/submit
) Biomed Central 